\title{
CONFIGURAÇÃO ELETRÔNICA NOS LIVROS DIDÁTICOS DE QUÍMICA DO PNLD 2018-2020: UM ESTUDO HISTÓRICO-CONCEITUAL
}

\author{
ELECTRON CONFIGURATION IN CHEMISTRY TEXTBOOKS PNLD 2018-2020: \\ A HISTORICAL-CONCEPTUAL STUDY
}

\author{
ADILSON LUÍS PEREIRA SILVA ${ }^{1}$ \\ JALDYR DE JESUS GOMES VARELA JÚNIOR ${ }^{2}$ \\ JACKSON RONIE SÁ-SILVA ${ }^{3}$ \\ HAWBERTT ROCHA COSTA ${ }^{4}$
}

\section{RESUMO}

0 entendimento das configurações eletrônicas constitui-se como um conhecimento fundamental em Química, pois permite explicar e prever diversas propriedades atômico-moleculares da matéria. Por este tema estar presente em livros didáticos de Química (LDQ), é relevante que sejam analisados, uma vez que norteiam a prática de muitos docentes. Neste sentido, o objetivo deste trabalho foi analisar como os autores dos LDQ aprovados no Programa Nacional do Livro Didático (2018-2020) têm abordado a configuração eletrônica do ponto de vista histórico-conceitual. Para isso, consultamos os trabalhos originais dos cientistas que contribuíram para o desenvolvimento da distribuição eletrônica (Thomson, Bohr, Stoner, Sommerfeld, Karapetoff, Madelung, Pauling e Yi), bem como outros trabalhos para avaliar a adequação histórica e conceitual. Os resultados destacam a necessidade de revisão dos LDQ, principalmente no que diz respeito à abordagem histórica, pois apresenta uma história individualista, em detrimento de uma abordagem mais contributiva para 0 entendimento da evolução do conceito.

Palavras-chave: Configuração Eletrônica. Livros Didáticos de Química. Ensino de Química.

\section{ABSTRACT}

The comprehension of electronic configurations is a fundamental knowledge in chemistry, allowing to explain and predicting several atomic-molecular properties of matter. Since this subject is present in chemistry textbooks (LDQ), it is relevant that they be analyzed, once guides the practice of many teachers. At all events, the objective of this work was to analyze how the authors of $L D Q$ approved in the Programa Nacional do Livro Didático (Brazilian Textbook Program) have been discussing the electronic configuration from a historical-conceptual point of view. For this, we consulted the original works of scientists who contributed to the development of electronic distribution (Thomson, Bohr, Stoner, Sommerfeld, Karapetoff, Madelung, Pauling and Yi), as well as others works to evaluate the historical and conceptual adequacy. The results highlight the need to review the $L D Q$, especially with regard to the historical approach, since it presents a story individualist, rather than a more contributive approach to understanding the evolution of the concept.

Keywords: Electron configuration. chemistry textbooks. chemistry teaching.

\footnotetext{
1 Mestre em Química pela Universidade Federal do Maranhão. Professor Assistente da Universidade Estadual do Maranhão. E-mail: adilson.luis@cecen.uema.br.0RCID: 0000-0002-8824-9980.

2 Doutor em Físico-Química pelo Instituto de Química de São Carlos. Professor do Colégio Universitário da Universidade Federal do Maranhão. E-mail: jaldyr.varela@ufma.br. ORCID: 0000-0001-8926-2696.

3 Doutor em Educação pela Universidade do Vale do Rio dos Sinos. Professor Adjunto da Universidade Estadual do Maranhão. E-mail: jacksonronie.uema@gmail.com. ORCID: 0000-0001-9607-3674.

4 Doutor em Educação para a Ciência. Universidade Federal do Maranhão. E-mail: hawbert@gmail.com. ORCID: 0000-0001-8460-9793.
} 


\section{CONFIGURAÇÃO ELETRÔNICA NO ENSINO DE QUÍMICA}

0 entendimento da configuração eletrônica se confunde com a descoberta dos elétrons, pois Thomson ao descobrir os corpúsculos negativos (hoje elétrons) se preocupou em como estariam organizados no novo modelo atômico proposto, agora divisível. Ele por meio de cálculos sugeriu que os elétrons se movimentariam em alta velocidade e seriam distribuídos de forma crescente em anéis concêntricos e coplanares (THOMSON, 1904; LOPES, 2009). Após o pontapé inicial, várias proposições, modificações e correções foram realizadas, em especial podemos citar as contribuições de Bohr, Stoner, Sommerfeld, Madelung e Pauling, para o que hoje conhecemos como configuração/ distribuição eletrônica de átomos.

Bianco e Meloni (2019, p. 148) apontam que a configuração eletrônica se apresenta como um dos "temas de maior dificuldade no ensino de Química no nível médio", devido ao alto grau de abstração. Apesar da complexidade, autores como Schwarz (2010) afirmam que a compreensão do ordenamento dos elétrons em níveis e subníveis é um dos principais tópicos dos cursos introdutórios de Química. Santos (2011) observou que alguns professores do ensino médio se equivocaram sobre a configuração eletrônica e o subnível mais energético do cálcio e do ferro, revelando, dessa forma, que os professores apresentam dificuldades. Carpenter (1983) afirmou que no ensino das configurações eletrônicas os alunos encontram dificuldade em lembrar a sequência de preenchimento dos orbitais, por isso propôs um diagrama para ajudar os alunos.

Nesse sentido, Scerri (2013) nos alerta que a versão da configuração eletrônica que foi ensinada a gerações de estudantes apresenta algumas falhas como, por exemplo, a não previsão das configurações anômalas e de possíveis inversões na energia dos subníveis. Já Darsey (1988) afirmou que os estudantes possuem dificuldade em distribuição eletrônica por níveis e subníveis, tal dificuldade está relacionada em desenhar as linhas diagonais presentes no diagrama de energia. França, Marcondes e Carmo (2009) concluíram que os estudantes confundem a distribuição eletrônica em níveis, quando há formação de íons.

Uma forma possível para solucionar essas dificuldades, relaciona-se ao desenvolvimento de mnemônicos, muitos exemplos são encontrados no periódico Journal of Chemical Education, por exemplo, citamos Hazlehurst (1941), Yi (1947), Hovland (1986), Garofalo (1997) e Kurushkin (2015). A proposta de Hazlehurst (1941) foi a primeira que citou o trabalho de Pauling (1939). 0 mnemônico de Yi (1947) é muito semelhante ao diagrama apresentado nos livros didáticos de Química. Já o de Hovland (1986) foi produzido usando tabuleiro de xadrez como um quadro de referência. 0 mnemônico de Garofalo (1997) foi elaborado utilizando casas, sendo que cada casa representa o número quântico principal (n), cada andar da casa corresponde ao número quântico azimutal (l) ou subnível e cada quarto representa o número quântico magnético (ml). Por fim, Kurushkin (2015) produziu um diagrama para promover 0 ensino da estrutura atômica a partir das regras de Madelung e Hund.

Então, por que estudar configuração eletrônica? A determinação da configuração eletrônica de átomos se apresenta como um conhecimento fundamental em Química e um conceito básico para a compreensão: a) das propriedades periódicas dos elementos; b) da reatividade; c) das ligações químicas (SALEHZADEH, MALEKI, 2016; ROZENTALSKI, PORTO, 2018; SCERRI, 2019a). Além disso, Pauling (1982, p. 53), em seu livro de Química Geral, afirmou que o estudo da Química pode ser simplificado a partir de uma boa compreeensão da estrutura eletrônica dos átomos, isto é, que "a Química seja mais fácil de entender e de lembrar". 


\section{HISTÓRIA DA QUÍMICA NOS LIVROS DIDÁTICOS DE QUIIMICA}

A História da Química $(\mathrm{HQ}$ ) como parte do conhecimento socialmente produzido, deve permear o ensino de Química, possibilitando ao aluno a compreensão do processo de elaboração do conhecimento com seus avanços, erros e conflitos. Chassot (2003), sugere que a inserção da HQ se reveste de um papel essencial para que 0 aluno desenvolva uma visão abrangente da Química em uma perspectiva de alfabetização científica. Assim, acreditamos que a inserção de episódios históricos contribui para um aprendizado mais significativo e contextualizado. A esse respeito Matthews (1995) aponta que a História da Ciência (HC) pode contribuir para:

[...] humanizar as ciências e aproximá-las dos interesses pessoais, éticos, culturais e políticos da comunidade; podem tomar as aulas de ciências mais desafiadoras e reflexivas, permitindo, deste modo, o desenvolvimento do pensamento crítico; podem contribuir para um entendimento mais integral de matéria científica, isto é, podem contribuir para a superação do "mar de falta de significação" que se diz ter inundado as salas de aula de ciências, onde fórmulas e equações são recitadas sem que muitos cheguem a saber o que significam; podem melhorar a formação do professor auxiliando o desenvolvimento de uma epistemologia da ciência mais rica e mais autêntica, ou seja, de uma maior compreensão da estrutura das ciências bem como do espaço que ocupam no sistema intelectual das coisas. (MATTHEWS, 1995, p. 165).

Já Oki (2002, p. 21) sugere que uma das maneiras de utilizar a HQ para melhorar o Ensino de Química consiste em realizar uma análise histórica da gênese dos "conceitos estruturantes" e da sua evolução ao longo do tempo. Porto (2011) propõe estudos de caso, em que se devem analisar, com certa profundidade, os episódios bem delimitados em HQ; superando a mera ilustração histórica do conteúdo, por exemplo, citando apenas datas, nomes do(s) químico(s) envolvido(s), ou curiosidade sobre sua vida pessoal; apresentando o contexto das ideias, problemas surgidos na época, às hipóteses discutidas, os fatores e debates que levaram ao abandono ou aceitação das hipóteses. A partir dessas duas propostas se promove a superação da concepção inadequada de que 0 conhecimento científico é algo pronto e acabado.

Por outro lado, autores como Chaves, Santos e Carneiro (2014), Leite e Porto (2015) e Targino e Baldinato (2016) analisando a abordagem histórica em Livros Didáticos de Química (LDQ), concluíram que os textos históricos têm contribuído com o desenvolvimento de concepções inadequadas de Ciência entre seus leitores como, por exemplo, uma visão dogmática e individualista, que contribue para uma compreensão de Ciência construída de forma linear e acumulativa, vale destacar que uma discussão mais aprofundada sobre as possíveis visões deformadas da ciência e como superá-las podem ser encontradas no livro de Cachapuz et al, (2005). Nesse sentido, tanto Cachapuz et al, (2005) quanto os autores que analisaram os LDQ concordam que o professor se aproxime da produção de historiadores modernos e que sejam desenvolvidos mais estudos sobre a inclusão da HQ nos LDQ.

Porto (2011, p. 165-166), a esse respeito, assevera que apenas a inclusão de HQ não é suficiente. Na verdade, sugere que deve haver a inserção da nova historiografia da Ciência tanto no ensino de Química quanto nos LDQ, esta abordagem "volta-se para a análise pontual e minuciosa de estudos de caso, buscando identificar a especificidade de episódios e documentos". Considerando, continuidades, rupturas e diferentes interpretações no empreendimento científico, bem como a consideração de fatores externos à ciência, como os de natureza psicológica e social. 
Assim, com base no exposto até aqui, o objetivo de nosso estudo foi analisar como é abordado o tema configuração/distribuição eletrônica sob uma perspectiva histórico-conceitual nos livros do PNLD (2018-2020), bem como propor adequações.

\section{PERCURSO METODOLÓGICO}

Inicialmente, definimos nossa análise com uma pesquisa documental de natureza qualitativa. A escolha pela análise documental reside no fato de se constituir em uma "técnica valiosa de abordagem de dados qualitativos, seja complementando as informações obtidas por outras técnicas, seja desvelando aspectos novos de um tema ou problema" (LÜDKE, ANDRÉ, 2018, p. 44-45). A nossa investigação se consistiu em uma análise, do ponto de vista histórico-conceitual, da temática configuração eletrônica encontrada nos capítulos dos livros de Química aprovados no PNLD 2018-2020, conforme apresentado no Quadro 1, e comparando-os com os trabalhos originais dos cientistas envolvidos na evolução do conceito das configurações eletrônicas como, por exemplo, Thomson, Bohr, Stoner, Sommerfeld, Karapetoff, Madelung, Pauling e Yi. Assim, avaliamos o ponto de vista histórico, isto é, como as contribuições dos cientistas foram abordadas nos LDQ, bem como a adequação dos conceitos apresentados, resultando em uma análise que chamamos de histórico-conceitual.

Quadro 1 - Lista dos Livros Didáticos de Química (LDQ) analisados.

\begin{tabular}{|c|l|}
\hline LDQ - A & FONSECA, M. R. M. Química, v. 1. 2. ed. São Paulo: Ática, 2016. \\
\hline LDQ - B & MORTIMER, E. F.; MACHADO, A. H. Química, v. 1. 2. ed. São Paulo: Scipione, 2013. \\
\hline LDQ - C & LISBOA, J. S. F. et al. Ser protagonista: química, v. 1. 3. ed. São Paulo: Edições SM, 2016. \\
\hline LDQ - D & NOVAIS, V. L. D.; ANTUNES, M. T. Vivá: Química, v. 1. Curitiba: Positivo, 2016. \\
\hline LDQ - E & CISCATO, C. A. M. et al. Química, v. 1. São Paulo: Moderna, 2016. \\
\hline LDQ - F & SANTOS, W. L. P.; MOL, G. S. (Coords.). Química cidadã, v. 1. 3. ed. São Paulo: Editora AJS, 2016. \\
\hline
\end{tabular}

Cabe destacar que o desenho metodológico desse estudo é apoiado nos trabalhos de Oki (2002) e de Leite e Porto (2015). Oki (2002) pontuou a possibilidade de se utilizar a HQ a partir de uma análise da evolução histórica, incluindo a gênese dos conceitos e comparando os avanços ao longo do tempo, em nosso trabalho o desenvolvimento do conceito se deu a partir da ideia inicial de Thomson até o diagrama mnemônico de Pao-Fang Yi. Já Leite e Porto (2015) propõem a criação de categorias/ tópicos de análise para propiciar a comparação entre os diferentes livros, entre os diferentes períodos históricos e entre os livros e os períodos históricos envolvidos. Nesse sentido, para a análise do conteúdo acerca das configurações eletrônicas, foram adotadas, após a leitura minuciosa dos capítulos, duas categorias analíticas, construídas a partir da técnica de análise categorial, que "funciona por operações de desmembramento do texto em unidades, em categorias segundo reagrupamentos analógicos" (BARDIN, 2016, p. 201), "a configuração/distribuição eletrônica" e "limitações da configuração/distribuição eletrônica”, para melhor discutirmos a comparação entre os LDQ e entre os LDQ com as referências originais.

Por fim, de acordo com o guia de Livros Didáticos de Química do Plano Nacional do Livro Didático - PNLD, a escolha do livro didático é de grande responsabilidade e exige muita atenção e 
cuidado (BRASIL, 2017). No guia são apresentados seis critérios de avaliação, o quarto se caracteriza pela "coerência do conhecimento químico na obra", subitem 4.1.3, pontua-se que a Química seja apresentada como uma "ciência de natureza humana marcada pelo seu caráter provisório, enfatizando as limitações de cada modelo explicativo, por meio de exposição de suas diferentes possibilidades de aplicação" (BRASIL, 2017, p. 17, grifo nosso). Esse ponto é crucial na análise deste artigo, como veremos ao longo da discussão dos resultados, a partir da comparação interna entre os LDQ e dos LDQ com as referências primárias, apresentando trechos e figuras originais produzidas pelos cientistas envolvidos no desenvolvimento das configurações eletrônicas.

\section{RESULTADOS E DISCUSSÃO}

\section{A CONFIGURAÇÃO/DISTRIBUIÇÃO ELETRÔNICA}

Nos LDQ C, D e E a descoberta da distribuição eletrônica, para átomos, foi atribuída ao físico dinamarquês Niels Bohr, pois, como apontado pelos autores do LDQ - C, "propôs que os elétrons se situam em níveis de energia, ou camadas eletrônicas - 1, 2, 3, 4, 5, 6 e 7 -, as quais também podem ser representadas pelas letras maiúsculas K, L, M, N, 0, P e Q" (LISBOA et al., 2016, p. 91). No entanto, os autores dos LDQ A e B optaram por detalhar a distribuição eletrônica em subníveis, o que entendemos ser mais adequado para 0 entendimento das configurações eletrônicas. Para ilustrar tal afirmação vejamos, no Quadro 2, a distribuição para o ferro em níveis de energia ${ }^{5}$, de acordo com os autores do LDQ - C.

Quadro 2 - Exemplo para a configuração eletrônica em níveis para o ferro.

\begin{tabular}{|c|c|l|}
\hline Elemento & Configuração & \multicolumn{1}{c|}{ Comentários } \\
\hline \multirow{3}{*}{${ }_{26} \mathrm{Fe}$} & $2-8-16$ & $\begin{array}{l}\text { Como o último nível possui entre 8 e } 18 \text { elétrons, permanecem 8 elétrons do último nível e o restante passa } \\
\text { para o próximo nível, que agora será o último. }\end{array}$ \\
\cline { 2 - 3 } & 2 - 8 - 8 - 8 & $\begin{array}{l}\text { Com o procedimento acima, temos agora 8 elétrons no último nível (nível de valência), isto significa, que } \\
\text { por essa configuração o Fe seria um gás nobre (baixa reatividade), mas isso não é observado. }\end{array}$ \\
\cline { 2 - 3 } & $2-8-14-2$ & $\begin{array}{l}\text { Configuração real para o Fe, apresentada no LDQ - C (LISBOA et al., 2016, p. 92), porém não explicada, } \\
\text { diz-se, simplesmente, que é a configuração aceita atualmente, em outras palavras, é colocada com uma } \\
\text { exceção à regra de distribuição eletrônica. }\end{array}$ \\
\hline
\end{tabular}

$$
\text { Fonte: Adaptado de Lisboa (2016, p. 92). }
$$

Apesar de os autores do LDQ - C atribuírem a configuração do ferro como uma exceção à regra, o mesmo não é encontrado no LDQ - A, pois este apresenta que para se poder obter a configuração eletrônica do Fe utilizando subníveis, por meio do diagrama de energia, tem-se " $1 s^{2} 2 s^{2} 2 p^{6} 3 s^{2} 3 p^{6}$ $4 s^{2} 3 d^{6}$ " (FONSECA, 2016, p. 174), tal configuração, em termos de níveis, tem-se 2 - 8 - 14 - 2. Vemos que a distribuição eletrônica do Fe, em relação aos níveis de energia, não constitui exceção, e pode ser encontrada após a distribuição por subníveis, que é mais adequada e completa.

No LDQ - B atribuiu-se o diagrama "em homenagem ao ilustre químico Linus Pauling (1901-1994), que deu várias contribuições para a aplicação da mecânica quântica à Química." (MORTIMER;

5 Ao explicar a distribuição eletrônica, nos LDQ C, D e E, os autores ainda utilizam camadas eletrônicas, quando deveriam considerar os níveis de energia, como orienta a IUPAC (JENKINS et al., 1991). 
MACHAD0, 2013, p. 203). Por outro lado, a autora do LDQ - A afirmou que "com base em um estudo detalhado da energia dos elétrons de um átomo, o cientista alemão Madelung desenvolveu empiricamente um diagrama de energia (que pode ser deduzido pela Mecânica Quântica)" (FONSECA, 2016, p. 173). Vale destacar que apenas a autora do LDQ - A apresentou a referência do Wong (1979) "Theoretical Justification of Madelung's Rule" para justificar o nome de Erwin Madelung atrelado à descoberta da distribuição eletrônica, mais especificamente as regras $(n+l, n)$.

Pelo reportado, vemos que não há consenso sobre a descoberta da distribuição eletrônica, o que poderia confundir professores e alunos. Na literatura também não há, pois autores como: Goudsmit e Richards (1964) atribuem à regra de preenchimento de elétrons, para átomos neutros, a Madelung (1936); Bianco e Meloni (2019) atribuem a Pauling (1939); Scerri (1991) atribuiu a Sommerfeld (1925/1926); Stoner (1924) atribuiu a Bohr (1922); Chaves, Santos e Carneiro (2014) atribuem à ideia inicial da distribuição eletrônica a Thomson (1904). Observamos que mesmo consultando referências originais é possível incorrer em atribuições equivocadas, daí a importância de uma leitura mais ampla e panorâmica, visando a construção de relatos históricos mais completos, desde a gênese do conceito, como proposto por Oki (2002).

Consultando os originais encontramos, no livro de Bohr (1922), que a distribuição eletrônica já era realizada em função dos níveis (n) e subníveis $(k)^{6}$, revelendo uma divergência com os LDQ C, $\mathrm{D}$ e E, pois os autores destes afirmaram que a proposição de Bohr era apenas em função dos níveis, no Quadro 2 mostramos como exemplo a distribuição para os gases nobres. Observamos, também, que a quantidade de elétrons por subnível varia com 0 aumento do número atômico (Z), por exemplo, o subnível 4 acomoda $4 \mathrm{e}^{-}$para $0 \mathrm{Kr}$, 6e- para 0 Xe e 8e- para $0 \mathrm{Rd}$, porém a quantidade total de elétrons nos níveis corresponde a mesma da atualidade (somatório de elétrons nos subníveis é igual ao total de elétrons nos níveis), mostrando, dessa forma, o alcance da previsão de Bohr.

Quadro 3 - Esquema de distribuição eletrônica para os gases nobres (GN) proposta por Bohr.

\begin{tabular}{|c|c|c|c|c|c|c|c|c|c|c|c|c|c|c|c|c|c|c|c|c|}
\hline \multirow{2}{*}{ GN } & \multirow{2}{*}{ Z } & \multicolumn{19}{|c|}{ Número de elétrons nas órbitas- $n_{k}$} \\
\hline & & $1_{1}$ & $2_{1}$ & $2_{2}$ & 3 & $3_{2}$ & $3_{3}$ & $4_{1}$ & $4_{2}$ & $4_{3}$ & $4_{4}$ & $5_{1}$ & $5_{2}$ & $5_{3}$ & $5_{4}$ & $6_{1}$ & $6_{2}$ & $6_{3}$ & $7_{1}$ & $7_{2}$ \\
\hline $\mathrm{He}$ & 2 & 2 & & & & & & & & & & & & & & & & & & \\
\hline $\mathrm{Ne}$ & 10 & 2 & 4 & 4 & & & & & & & & & & & & & & & & \\
\hline $\mathrm{Ar}$ & 18 & 2 & 4 & 4 & 4 & 4 & & & & & & & & & & & & & & \\
\hline $\mathrm{Kr}$ & 36 & 2 & 4 & 4 & 6 & 6 & 6 & 4 & 4 & & & & & & & & & & & \\
\hline$X_{e}$ & 54 & 2 & 4 & 4 & 6 & 6 & 6 & 6 & 6 & 6 & - & 4 & 4 & & & & & & & \\
\hline $\mathrm{Rd}$ & 86 & 2 & 4 & 4 & 6 & 6 & 6 & 8 & 8 & 8 & 8 & 6 & 6 & 6 & - & 4 & 4 & & & \\
\hline$?^{7}$ & 118 & 2 & 4 & 4 & 6 & 6 & 6 & 8 & 8 & 8 & 8 & 8 & 8 & 8 & 8 & 6 & 6 & 6 & 4 & 4 \\
\hline
\end{tabular}

Para ilustrar vejamos que a configuração, em níveis de energia, do Oganessônio $\left({ }_{118} 0 \mathrm{~g}\right)$ é 2 - 8 - 18 - 32 - 32 - 18 - 8, que a princípio seria o último elemento da tabela periódica. Observamos que a notação de Bohr e a atual apresentam similaridade apenas para o primeiro subnível, isto é,

6 No modelo de Bohr-Sommerfeld utilizava-se a letra k para os subníveis, com o modelo atual passou-se a utilizar a letra I, mas existe uma relação entre as duas representações $(l=k-1)$.

7 Quando Bohr publicou seu trabalho o elemento $0 \mathrm{~g}$ ainda não havia sido descoberto, por isso ele colocou a interrogação (?) para o número atômico 118. 
$1_{1}=1 \mathrm{~s}$, cada um com 2 elétrons. Por outro lado, o mesmo comportamento não é observado para os outros níveis, por exemplo, no quarto nível $4_{1}\left(8 \mathrm{e}^{-}\right) \neq 4 \mathrm{~s}\left(2 \mathrm{e}^{-}\right) ; 4_{2}\left(8 \mathrm{e}^{-}\right) \neq 4 \mathrm{p}\left(6 \mathrm{e}^{-}\right) ; 4_{3}\left(8 \mathrm{e}^{-}\right) \neq 4 \mathrm{~d}$ $\left(10 \mathrm{e}^{-}\right) ; 4_{4}\left(8 \mathrm{e}^{-}\right) \neq 4 \mathrm{f}\left(14 \mathrm{e}^{-}\right)$. Mas isso começou a mudar com a contribuição de Stoner (1924) sobre a quantidade máxima de elétrons em cada subnível, por exemplo, $04_{1}$ passou a ser $4_{11}\left(n_{k j}\right)^{8}$ em que a quantidade máxima seria de dois elétrons, porém até a modelagem atual muitas contribuições científicas foram necessárias para evolução conceitual da configuração eletrônica.

Na Figura 1 temos o diagrama proposto por Pauling em 1957 - esse diagrama é uma versão mais completa do que a versão prévia publicada em 1939, em que os orbitais aparecem vazios (PAULING, 1939) -, um diagrama relativamente complexo para a distribuição de elétrons em níveis e subníveis dos elementos químicos existentes na época. Nessa configuração a distribuição eletrônica mostrada na Figura 1 já considerava os números quânticos atuais n (número quântico principal), I (número quântico secundário), ml (número quântico magnético) e $\mathrm{m}_{\mathrm{s}}$ (número quântico de spin).

Figura 1 - Esquema para o diagrama de energia proposto por Pauling.

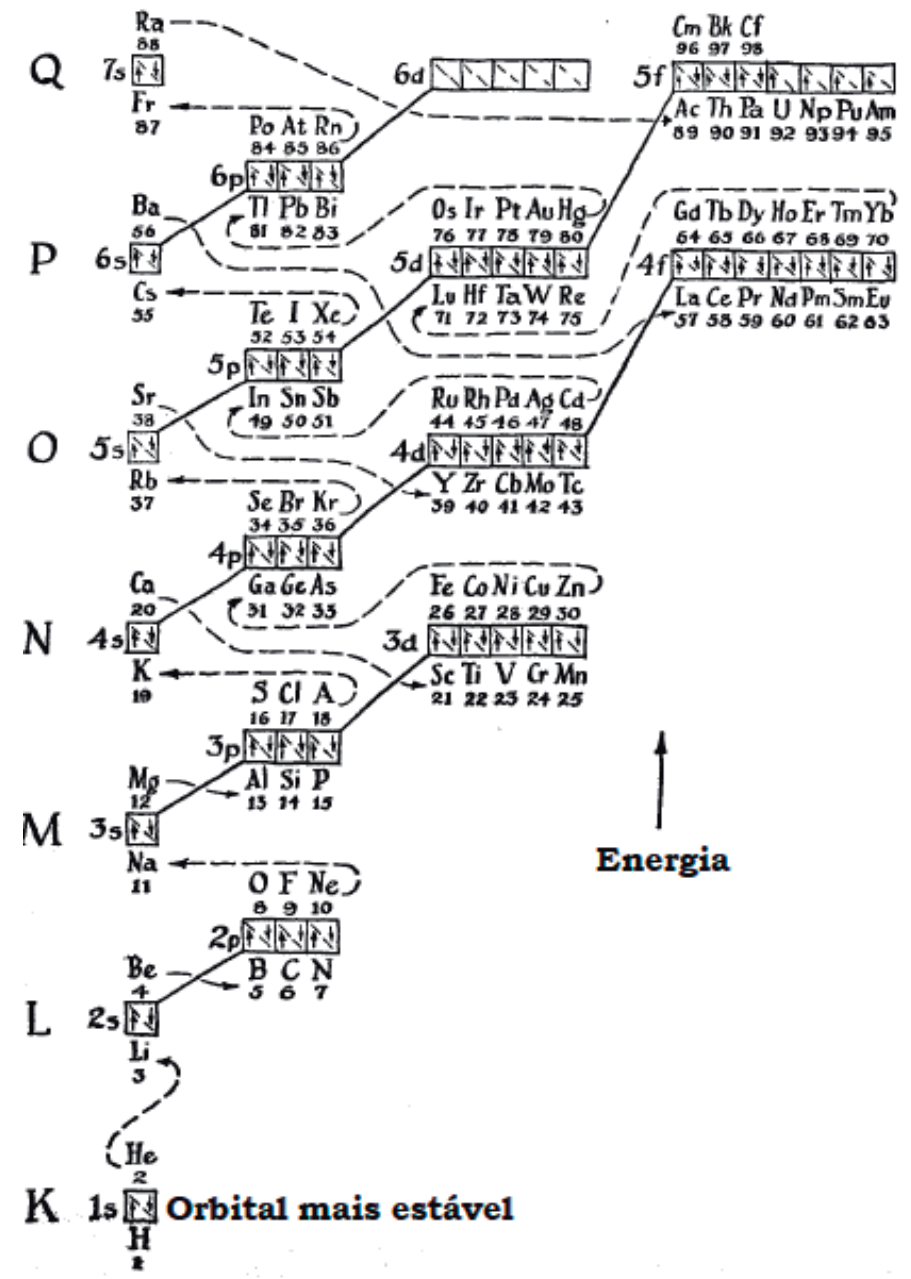

Fonte: Pauling (1957, p. 96).

8 Na notação $n_{k j}$ o n é o número quântico principal, o k é o número quântico azimutal e 0 j é o número quântico interno $\left(1=2 e^{-;} 2=4 e^{*} ; 3=\right.$ $\left.6 \mathrm{e}^{-;} 4=8 \mathrm{e}^{-}\right)$. 
Ao comparamos o diagrama apresentado por Pauling, observamos que este em nada se assemelha aos diagramas apresentados pelos autores do LDQ - B, conforme mostrado na Figura $2 b$, inclusive, a partir da comparação entre os diagramas apresentados nos livros didáticos de Química com o proposto por Pauling, não é possível explicar o porquê de as linhas serem diagonais, pois tal entendimento deriva da contribuição de Madelung, que será apresentada mais a frente, e não somente do diagrama de Pauling $(1939,1957)$. Dessa forma, parece-nos que a atribuição dada pelos autores do LDQ - B estaria equivocada, em outros termos, é necessário apresentar as outras contribuições para se chegar ao diagrama que aparece nos livros, uma possibilidade é consultar as referências originais dos cientistas envolvidos e as referências secundárias baseadas na nova historiografia da Ciência, bem como entender a evolução do conceito de configuração eletrônica, desde sua gênese, como realizado neste trabalho.

0 diagrama mostrado na Figura 2a é atribuído a Erwin Madelung (FONSECA, 2016), o leitor pode observar que 0 diagrama da Figura 2a é mais completo do que 0 apresentado na Figura 2b, mostrando uma continuidade além do $Z=118$, vide os três pontinhos abaixo do 7 s. Ou seja, no diagrama mostrado pela autora do LQD - A existe a possibilidade, por exemplo, de elementos com números atômicos 119 (Eka-Frâncio), 120 (Eka-Rádio), inaugurando o subnível 8s, vale destacar que tal previsão já fora relatada por Scerri (2019a), pois afirma que existem várias colaborações internacionais trabalhando ativamente para sintetizar os elementos 119 e 120, bem como novos elementos com número atômico maior que 120 (Z > 120), já previstos de forma teórica por Umemoto e saito (1996).

Figura 2 - Diagramas esquemáticos apresentados nos LDQ - A (a) e LDQ - B (b).

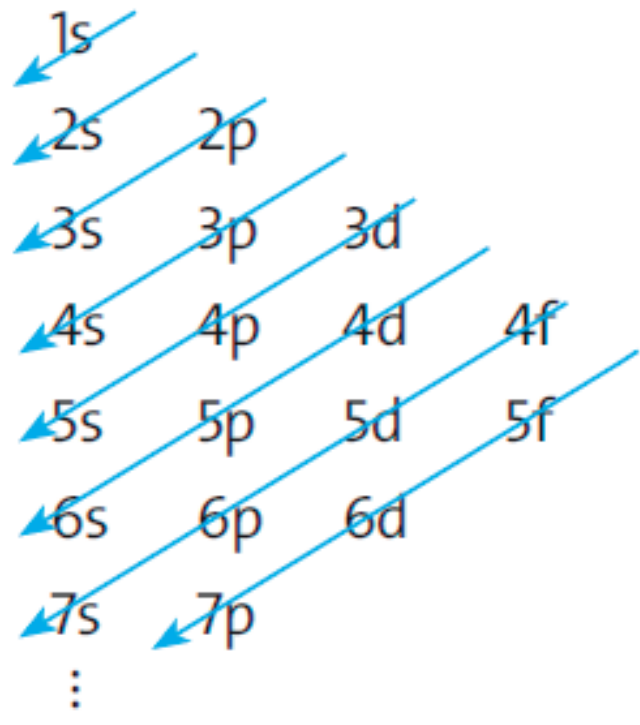

(a)
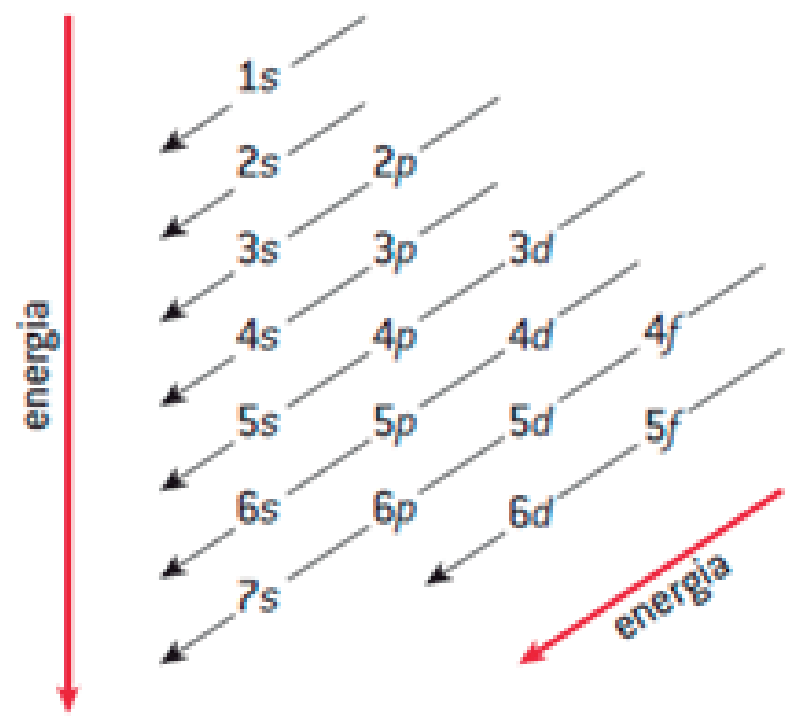

(b)

Fonte: Fonseca (2016, p. 173) e Mortimer e Machado (2013, p. 202). 
No entanto, um diagrama similar ao apresentado no LDQ - B é obtido no artigo publicado, em 1947, por Pao-Fang Yi, que é mostrado na Figura 3, note que na proposição de Yi (1947) os subníveis apresentam uma numeração crescente dentro dos parênteses variando do 1s (1) até $06 \mathrm{~d}$ (17). 0 leitor pode observar que enquanto a energia aumenta de baixo para cima no diagrama de Yi (1947), assim como 0 diagrama publicado por Pauling (1957), nos LDQ A e B o aumento da energia é de cima para baixo, tal interpretação é corroborada pela análise de Bianco e Meloni (2019). Assim, parece-nos razoável que Pao-Fang Yi deveria ter sido citado nos livros como o pesquisador que desenvolveu um diagrama de energia a partir dos trabalhos de Madelung (1936) e de Pauling (1939).

Figura 3 - Esquema para o diagrama de energia proposto por Yi.

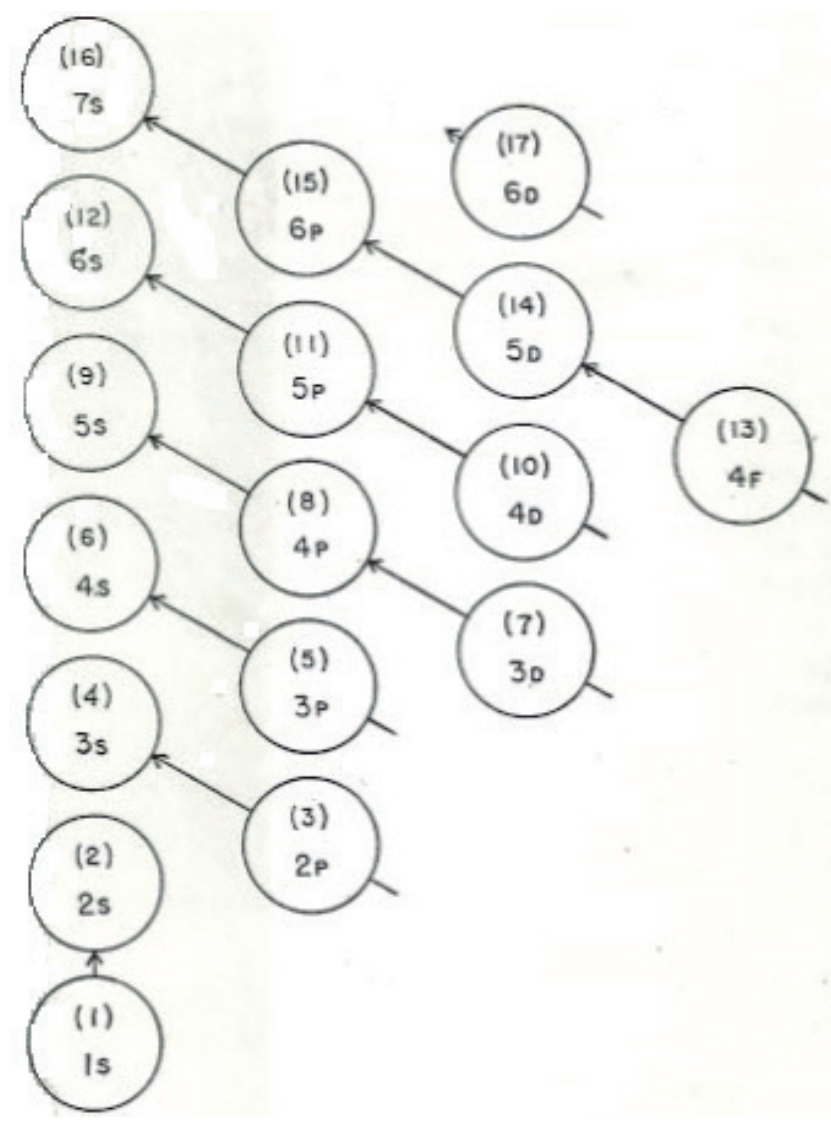

Fonte: Yi (1947, p. 567).

Ao consultarmos o livro de Madelung (1936) não encontramos nenhum diagrama que justificasse a atribuição, porém há uma tabela organizada em ordem crescente de número atômico e de $\mathrm{n}+\mathrm{l}$, bem como apresenta os valores de $\mathrm{ml}$ e $\mathrm{ms}$, ver Figura 4. 
Figura 4 - Tabela proposta por Madelung para a distribuição eletrônica.

\begin{tabular}{|c|c|c|c|c|c|c|c|c|c|c|c|c|c|c|c|c|c|c|c|}
\hline \multirow{2}{*}{$z$} & & & II & & IV & III & & + & & & & I & III & \multirow[b]{2}{*}{2} & \multirow[t]{2}{*}{ IV } & \multirow{2}{*}{$\frac{\text { III }}{s}$} & \multirow{2}{*}{ 离 } & \multirow{2}{*}{\multicolumn{2}{|c|}{$\frac{7}{4}$}} \\
\hline & & 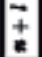 & $m$ & $t$ & $m$ & & ప్ & ฝ & & & & 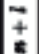 & $n$ & & & & & & \\
\hline 1 & $\mathbf{H}$ & 1 & 1 & 0 & 0 & & 0 & 2 & & 52 & $\mathrm{Te}$ & & 15 & & & & 1 & 3 & \\
\hline 2 & $\mathrm{He}$ & 1 & 1 & 0 & 0 & $-1 / 9$ & 0 & 1 & is & 53 & $\mathbf{J}$ & 6 & 5 & 1 & & & 1 & 2 & \\
\hline 3 & $\mathbf{L i}$ & 2 & 2 & $\overline{0}$ & 0 & +1 & 0 & 2 & 2S & & & 6 & 5 & 1 & & & 0 & & \\
\hline 4 & $\mathrm{Be}$ & 2 & 2 & 0 & 0 & $\begin{array}{r}18 \\
-1 / 9\end{array}$ & 0 & 1 & is & 55 & Cs & 6 & 6 & 0 & 0 & $+1 / 2$ & 0 & 2 & 'S \\
\hline 5 & B & 3 & 2 & 1 & -1 & & 1 & 2 & & 56 & $\mathbf{B a}$ & 6 & 6 & 0 & 0 & $-1 / 2$ & 0 & 1 & is \\
\hline 6 & C & 3 & 2 & i & & & $i$ & 3 & & 7 & $\mathbf{L a}$ & 7 & 4 & 3 & -3 & & 3 & 2 & ${ }^{2} \mathbf{F}$ \\
\hline 7 & $\mathbf{N}$ & 3 & 2 & 1 & +1 & & 0 & 4 & 4 & 58 & $\mathrm{Ce}$ & 7 & 4 & 3 & -2 & & 5 & 3 & ${ }^{8} \mathbf{H}$ \\
\hline 8 & o & 3 & 2 & 1 & +1 & $-1 / 2$ & 1 & 3 & & & $\mathbf{P r}$ & 7 & 4 & 3 & -1 & & 6 & 4 & $\mathbf{I}$ \\
\hline 1 & $\begin{array}{l}\mathrm{F} \\
\mathrm{Ne}\end{array}$ & $\begin{array}{l}3 \\
3\end{array}$ & $\begin{array}{l}2 \\
2\end{array} \mid$ & 1 & $\begin{array}{r}0 \\
-\end{array}$ & -1 & $\begin{array}{l}1 \\
0\end{array}$ & 2 & IP & $\begin{array}{l}\infty \\
61\end{array}$ & II & 7 & $\begin{array}{l}4 \\
4\end{array}$ & 3 & $\begin{array}{r}0 \\
+1\end{array}$ & & 5 & & ${ }^{*} \mathbf{H}$ \\
\hline 11 & $\mathrm{Na}$ & 3 & 3 & $\frac{1}{0}$ & & + & . & 1 & Is & 62 & Sm & 7 & 4 & 3 & +2 & & 3 & & ${ }^{2} \mathbf{F}$ \\
\hline 12 & $\mathrm{Mg}$ & 3 & 3 & 0 & 0 & $\frac{18}{-1 / 2}$ & 0 & 1 & is & 6 & Eu & 7 & 4 & 3 & +3 & & 0 & 8 & S \\
\hline 13 & Al & 4 & 3 & 1 & -1 & $+1 / 4$ & 1 & 2 & PP & $\begin{array}{l}64 \\
65\end{array}$ & Gd & 7 & 4 & 3 & +3 & $-1 / \mathrm{s}$ & 3 & 7 & TF \\
\hline & $S$ & 4 & 3 & 1 & & & $i$ & 3 & & 6 & & 7 & 4 & 3 & +2 & - & 5 & 6 & ${ }^{6} \mathbf{H}$ \\
\hline 15 & $\mathbf{P}$ & 4 & 3 & 1 & +1 & $+1 / 2$ & o & 4 & & 67 & Ho & 7 & 4 & 3 & $\begin{array}{l}1 \\
0\end{array}$ & $=1$ & 6 & 4 & I \\
\hline 16 & $\mathbf{s}$ & 14 & 3 & 1 & +1 & & 1 & 3 & & 68 & $\mathbf{E r}_{r}$ & 7 & 4 & 3 & -1 & -1 & 5 & 3 & H \\
\hline 17 & Cl & 4 & 3 & 1 & 0 & -1 & 1 & 2 & & 69 & $\mathrm{Tm}$ & 7 & 4 & 3 & -2 & & 3 & 2 & F \\
\hline 18 & $\mathbf{A}$ & 4 & 3 & 1 & -1 & $-1 / 2$ & 0 & 1 & is & 70 & $\mathbf{Y b}$ & 7 & 4 & 3 & -3 & $-1 / \mathrm{a}$ & 0 & 1 & is \\
\hline 19 & K & 4 & 4 & 0 & 0 & $+1 / 2$ & 0 & 2 & 'S & 71 & $C_{p}$ & 7 & 5 & 2 & -2 & & 2 & 2 & $2 D$ \\
\hline 20 & $\mathrm{Ca}$ & 4 & 4 & 0 & 0 & & o & 1 & is & 72 & Hif & 7 & 5 & 2 & -1 & & 3 & 3 & \\
\hline 21 & $\mathrm{Sc}$ & 5 & 3 & 2 & -2 & - & 2 & 2 & & 73 & $T_{a}$ & 7 & 5 & 2 & & & 3 & 4 & $\mathbf{F}$ \\
\hline & $T \mathbf{i}$ & 5 & 3 & 2 & -1 & & 3 & 3 & & & W & 7 & 5 & & +1 & & 2 & 5 & D \\
\hline 23 & $\mathbf{v}$ & & 3 & 2 & 0 & +1 & 3 & 4 & & 75 & Re & 7 & 5 & 2 & +2 & & & & es \\
\hline & C. & & 3 & 2 & +1 & $+1 / 2$ & 2 & 5 & & & $\mathrm{Os}$ & & 5 & 2 & +2 & & 2 & & SD \\
\hline 2. & Mn & 5 & 3 & 2 & +2 & +1 & 0 & 6 & & 77 & Ir & 7 & 5 & 2 & +1 & & 3 & 4 & \\
\hline 26 & Fe & & & 2 & +2 & $=$ & 2 & 5 & & & Pt & 7 & 5 & 2 & & -1 & 3 & 3 & F $F$ \\
\hline 2 & Co & 5 & & 2 & +1 & -17 & 3 & 4 & & 79 & $\mathbf{A u}$ & 7 & 5 & & -1 & & 2 & & \\
\hline 28 & Ni & 5 & 3 & 2 & 0 & -1 & 3 & 3 & & 80 & Hg & 7 & 5 & 2 & -2 & & 0 & 1 & is \\
\hline & C & & & 2 & -1 & $-1 / 2$ & 2 & 2 & & 81 & T1 & 7 & 6 & 1 & -1 & $t$ & 1 & & \\
\hline $3 c$ & $\mathrm{Zn}_{\mathbf{n}}$ & 5 & 3 & 2 & -2 & -1 & 0 & 1 & 15 & 82 & $\mathbf{P b}$ & 7 & 6 & 1 & 0 & & 1 & 3 & $P_{P}$ \\
\hline 3 & G & & & 1 & -1 & $+1 / 2$ & 1 & 2 & & & & & & & +1 & & 0 & & \\
\hline 3. & Ge & 5 & & 1 & 0 & & 1 & 3 & & 84 & Po & 7 & 6 & 1 & +1 & & 1 & 3 & ${ }^{2} \mathrm{P}$ \\
\hline 33 & As & & 4 & 1 & +1 & & 0 & 4 & & 85 & At & 7 & 6 & 1 & & & 1 & 2 & ${ }^{*} P$ \\
\hline 3 & Se & 5 & 4 & 1 & +1 & & 1 & 3 & & 86 & Em & 7 & 6 & 1 & -1 & & 0 & 1 & is \\
\hline 3. & $\mathrm{Br}$ & 5 & 4 & 1 & & & 1 & 2 & & 87 & $F_{\mathbf{r}}$ & 7 & 7 & 0 & 0 & & 0 & 2 & "S \\
\hline & $\mathbf{K r}$ & 5 & 4 & 1 & -1 & & 0 & 1 & & 88 & $\mathbf{R a}$ & 7 & 7 & 0 & 0 & & 0 & 1 & ${ }^{1} \mathrm{~S}$ \\
\hline 37 & $\mathbf{R b}$ & 5 & 5 & 0 & 0 & & 0 & 2 & & 89 & Ac & 8 & 5 & 3 & -3 & & 3 & & 'F \\
\hline 38 & $\mathrm{Sr}$ & 5 & 5 & 0 & 0 & -1 & 0 & 1 & & & Th & 8 & 5 & & & & 5 & & \\
\hline 39 & $\mathbf{Y}$ & 6 & 4 & 2 & -2 & & 2 & 2 & & 9 & $\mathbf{P}_{\text {. }}$ & 8 & 5 & 3 & -1 & & 6 & 4 & \\
\hline & $\mathbf{Z r}_{r}$ & 6 & 4 & 2 & -1 & & 3 & 3 & & 92 & $\mathbf{U}$ & 8 & 5 & 3 & & & 6 & & \\
\hline 4 & Nb & 6 & 4 & 2 & & & 3 & 4 & & 9 & Np & 8 & 5 & 3 & +1 & & 5 & & \\
\hline 42 & Mo & 6 & 4 & 2 & +1 & & 2 & 5 & & & $\mathbf{P a}$ & 8 & 5 & 3 & & & 3 & & \\
\hline 43 & Tc & 6 & 4 & 2 & +2 & & 0 & 6 & & 95 & Am & 8 & 5 & & +3 & & 0 & 8 & s \\
\hline 44 & Ru & 6 & 4 & 2 & +2 & & 2 & 5 & & 96 & Cm & 8 & 5 & 3 & +3 & & 3 & & \\
\hline & $\mathbf{R h}$ & 6 & 4 & 2 & +1 & & 3 & 4 & & 97 & Bk & 8 & 5 & & +2 & & 5 & & \\
\hline 4 & Pd & 6 & 4 & 2 & & $-2 / 2$ & 3 & & 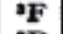 & 9 & Cf & 8 & 5 & & +1 & & 6 & & \\
\hline 4 & Ag & 6 & 4 & 2 & -1 & & 2 & 2 & & & & & & 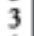 & & -1 & 6 & & 4 \\
\hline 4. & Cd & 6 & 4 & 2 & -2 & $-1 / 2$ & 0 & 1 & 1 & 10 & - & 8 & 5 & 3 & -1 & -1 & 5 & & ${ }^{\circ} \mathrm{H}$ \\
\hline 49 & In & 6 & 5 & & -1 & $+1 / 2$ & 1 & 2 & & & - & & & & & & 3 & & 1 \\
\hline 50 & Sn & 6 & & & & & 1 & & & & & & & & -3 & & 0 & 1 & ${ }^{\mathrm{S}} \mathrm{S}$ \\
\hline 51 & Sb & & & & & & & & & & - & & & & -2 & & & & \\
\hline
\end{tabular}

Fonte: Madelung (1936, p. 360).

Goudsmit e Richards (1964) afirmam que apesar do trabalho de Madelung ter sido publicado em 1936, ele já tinha o desenvolvido em 1926, nesse intervalo Karapetoff (1930) publicou uma versão ainda utilizando a notação de Bohr $\left(n_{k}\right)$, ou seja, propôs a regra $n+k$. Vemos aqui que as descobertas científicas não são obtidas tão rapidamente como se pode imaginar, mas sim fruto de muito trabalho 
e tempo para resolver os problemas da época que irão gerar ou não novos conhecimentos. Por outro lado, Stewart (2010) citando um trabalho original de Charles Janet, afirma que as regras $(n+l, n)$ deveriam ser atribuídas a Janet, pois este as publicou seis anos antes da proposta de Madelung. Além disso, utilizando essa ideia, Charles Janet publicou uma tabela periódica em que cada linha corresponderia a um valor de $n+I$ (STEWART, 2010), e Scerri (2019a) complementa mostrando uma versão da Tabela de Janet, na qual já existem os espaços para os elementos 119 e 120.

Assim, cabe destacar que a proposta de Madelung já incluía o princípio da exclusão de Pauli e a regra da multiplicidade máxima de Hund (MIESSLER; TARR, 2004), bem como utilizava os números quânticos atuais e, diferentemente do diagrama de Pauling $(1939,1957)$, explicava a origem das linhas diagonais, a partir de duas regras empíricas, chamadas de regras de Madelung, para o preenchimento eletrônico dos átomos neutros: 1) a ordem de preenchimento dos orbitais é dada pela soma dos números quânticos $n+l$; 2) para valores iguais de $n+l$, o preenchimento aumenta com 0 valor de n. Madelung (1936, p. 359) afirmou ainda que "apenas a justificativa teórica destas regras ainda não estão disponíveis". A comprovação teórica, baseada em mecânica quântica, foi proposta, incialmente por Klechkowskii (1962) e revisada por Wong (1979) - artigo citado pela autora do LDQ - A.

Outro ponto de destaque é que, nos livros analisados, não encontramos nenhuma referência aos trabalhos/contribuições de Arnold Sommerfeld e de Joseph J. Thomson, mas há na literatura especializada, por exemplo, os trabalhos de Allen e Knight (2002), de Scerri (1991) e de Chaves, Santos e Carneiro (2014). Desse modo, parece-nos que os autores dos livros didáticos estão mais interessados em apenas citar um nome para a descoberta das configurações eletrônicas e fortalecer uma concepção individualista de Ciência (CACHAPUZ et al., 2005), do que 0 de promover uma discussão mais contextual e alargada do ponto de vista histórico, conforme as proposições de Matthews (1995) e Porto (2011), em que se devem vislumbrar as contribuições dos cientistas, as evoluções e as contradições, o papel da comunidade científica da época na aceitação ou abandono do conceito/conhecimento construído, superando, dessa forma, o que Allchin (2004) chamou de pseudo-história.

Nesse sentido, sugerimos que a abordagem histórica para a distribuição eletrônica deve considerar: i) a articulação entre as referências originais (ou primárias) dos cientistas envolvidos desde a sua gênese, com Thomson, até a concepção atual do mnemônico de Pao-Fang Yi, mostrando aos estudantes que a construção do conceito é uma atividade humana, com as suas continuidades e rupturas, evitando o que nós, historiadores da Ciências, chamamos de "presentismo"; ii) a utilização de referências secundárias, desde que devidamente baseadas na nova historiografia da ciência, como os trabalhos de Chaves, Santos e Carneiro (2014) e de Bianco e Meloni (2019). Contudo, reconhecemos que essa tarefa não é fácil, conforme já apontado por Beltran, Saito e Trindade (2014, p. 103), quando relatam a complexidade de se "colocar em prática intenções e recomendações sobre 0 uso da História da Ciência no ensino", pois envolvem a "construção de interfaces entre pelo menos duas áreas distintas".

Na literatura, há evidências de que Arnold Sommerfeld tenha sido o primeiro a publicar uma forma preliminar para o diagrama de energia em função dos níveis e subníveis (ALLEN; KNIGHT, 2002; SCERRI, 1991), veja a Figura 5. Scerri (1991, p. 445) ainda afirma que não pôde "resistir a participar neste debate, ressaltando que, até esta data, ninguém citou o verdadeiro criador da ideia [do diagrama mnemônico] que foi Sommerfeld". 
Figura 5 - Diagrama esquemático de energia proposto por Sommerfeld.

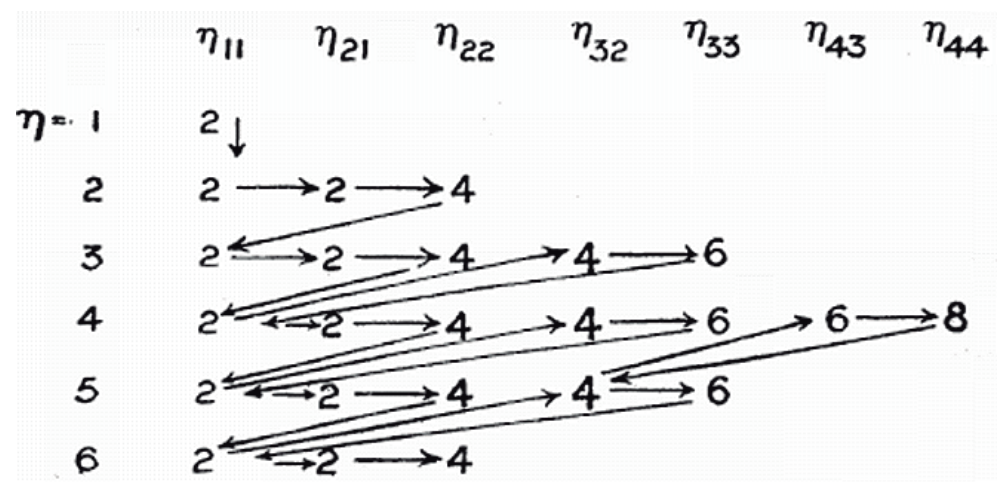

Fonte: Sommerfeld (1925/1926, p. 144).

Na Figura 5 a ordem energética é a mesma observada nos LDQ, isto é, a energia cresce de cima para baixo. Além disso, cabe destacar dois pontos: 1) a quantidade máxima de elétrons por subnível é a mesma da atual, por exemplo, para o quarto nível: $4 n_{11}=4 \mathrm{~s}$, com $2 \mathrm{e}^{-;} 4\left(\mathrm{n}_{21}+\mathrm{n}_{22}\right)=4 \mathrm{p}$, com $6 \mathrm{e}^{-*}$; $4\left(\mathrm{n}_{32}+\mathrm{n}_{33}\right)=4 \mathrm{~d}$, com 10e; $4\left(\mathrm{n}_{43}+\mathrm{n}_{44}\right)=4 \mathrm{f}$, com 14e-; porém tal quantidade já havia sido sugerida por Stoner em 1924; 2) na distribuição após o preenchimento do subnível $3\left(\mathrm{n}_{21}+\mathrm{n}_{22}\right)$ o próximo será $04 n_{11}$ e não $03\left(n_{32}+n_{33}\right)$, isto quer dizer, em termos atuais, que após o preenchimento do subnível $3 p$ virá 0 4s e não 0 3d, mostrando, 0 alcance da previsão de Sommerfeld. Nesse sentido, acreditamos que a contribuição de Sommerfeld no desenvolvimento da configuração eletrônica dos átomos neutros deve figurar nos LDQ.

Thomson, por sua vez, propôs a primeira distribuição eletrônica para átomos neutros em 1904, a partir do seu modelo atômico, conforme afirmam Lopes (2009) e Chaves, Santos e Carneiro (2014). Inclusive, nesses trabalhos encontramos a correção de um equívoco histórico relacionado ao modelo atômico de Thomson. Pois ao analisarmos os capítulos relacionados aos modelos atômicos, observamos que cerca de 70\% dos livros de química do PNLD 2018-2020 apresentam o modelo de forma estática (LDQ A, B, C e D), no entanto, a proposição de Thomson já possuía natureza dinâmica, como apontado pelos autores dos LDQ E e F em que os elétrons estariam "dispostos em uma série de anéis concêntricos e em constante movimento em seu interior" (CISCATO et al., 2016, p. 91). A partir desse breve relato, observamos a necessidade de (re)visitar as referências primárias para reconstrução histórica de conceitos. Ainda sobre a distribuição eletrônica, Thomson afirmou que:

[...] o número de corpúsculos dispostos em uma série de anéis paralelos, varia de um anel para anel: cada corpúsculo está viajando em alta velocidade em torno da circunferência do anel em que está situado, e os anéis estão organizados de modo que aqueles que contêm um grande número de corpúsculos estão próximos da superfície da esfera, enquanto aqueles em que há um número menor de corpúsculos estão mais para o interior da esfera. (Thomson, 1904, p. 254-255, grifo nosso).

Observamos pelo excerto acima que Thomson apresentou a primeira ideia de distribuição eletrônica. Vale lembrar ao leitor, que nessa época ainda não haviam sido descobertos os números quânticos (n, l, ml e ms $)$, essa distribuição proposta por Thomson foi superada ao longo do tempo, 
mas a sua contribuição foi fundamental para o início das discussões acerca da distribuição dos corpúsculos eletricamente negativos (elétrons). No Quadro 4 apresentamos a proposta inicial de Thomson, a partir de cálculos, para a distribuição destes corpúsculos negativos.

Quadro 4 - Distribuição eletrônica proposta por Thomson.

\begin{tabular}{|c|c|c|c|c|c|c|}
\hline Número total de elétrons & 60 & 55 & 50 & 45 & 40 & 35 \\
\hline & 20 & 19 & 18 & 17 & 16 & 16 \\
Número sucessivo de & 16 & 16 & 15 & 14 & 13 & 12 \\
elétrons nos anéis & 13 & 12 & 11 & 10 & 8 & 6 \\
& 8 & 7 & 5 & 4 & 3 & 1 \\
& 3 & 1 & 1 & & & \\
\hline Número total de elétrons & 30 & 25 & 20 & 15 & 10 & 5 \\
\hline & 15 & 13 & 12 & 10 & 8 & 5 \\
Número sucessivo de & 10 & 9 & 7 & 5 & 2 & \\
elétrons nos anéis & 5 & 3 & 1 & & & \\
\hline
\end{tabular}

Fonte: Adaptado de Thomson (1904, p. 257).

Analisando 0 Quadro 4, observamos que o número de elétrons é proporcional ao número de anéis e, por exemplo, os átomos com um total de $5 \mathrm{e}^{-}, 15 \mathrm{e}^{-}, 35 \mathrm{e}^{-}$e $60 \mathrm{e}^{-}$apresentam um, dois, três, quatro e cinco anéis, respectivamente. Observe que esses anéis, em última análise, podem ser considerados como os níveis atuais. Nesse contexto, observamos que é necessária uma reconstrução histórica abrangente com as problemáticas da época, que vise superar aquelas concepções inadequadas de Ciência levantadas por Cachapuz et al, (2005). Vidal e Porto (2012, p. 303) relataram que não se pode desconsiderar que as informações sobre a "história da ciência, presentes nos livros didáticos [...], podem influenciar as visões de ciência que serão construídas pelos alunos em seu processo de aprendizagem em ciências - dada a importância do livro didático como referência do saber escolar". Sepini e Maciel (2016) acrescentam que no Ensino de Ciências a HC é inseparável dos conteúdos escolares, daí a importância da discussão de aspectos históricos, baseados na nova historiografia da Ciência, na formação de professores de ciências.

Em nossa análise, a abordagem histórica apresentada nos LDQ retrata uma história de um único personagem (concepção individualista), em detrimento de uma abordagem mais contributiva da participação de outros cientistas e da comunidade científica, para o entendimento da evolução do conceito de configuração/distribuição eletrônica. Resultado similar foi obtido por Almeida e Falcão (2005, p. 18), analisando livros didáticos de Biologia adotados no Brasil, pois, em vários livros, a abordagem do tema é apresentada de forma final, sendo desprovida "de contextualização histórica para a compreensão, por parte dos alunos, de como os conceitos foram desenvolvidos ao longo do tempo".

A esse respeito, Fernandes e Porto (2012, p. 429) pontuam que abordagens mais profundas da HQ "podem auxiliar 0 estudante em diferentes aspectos de seu aprendizado: na construção de conceitos de química; na compreensão da complexidade da atividade científica ao longo do tempo; bem como no entendimento do fazer científico na atualidade". Além disso, Pires, Abreu e Messeder (2010, p. 6) acrescentam que "0 estudo apenas conceitual não traz aprendizagem, justifica-se então 
a necessidade da abordagem com envolvimento histórico". Mostrando, dessa forma, a importância da nossa proposta por um estudo histórico-conceitual.

\title{
LIMITAÇÕES DA CONFIGURAÇÃO/DISTRIBUIÇÃO ELETRÔNICA
}

A partir da análise dos LDQ, observamos um consenso ao afirmar que a distribuição eletrônica é válida para a maioria dos átomos existentes, conforme os excertos mostrados abaixo: "Se você seguir a ordem dos subníveis indicada pelas linhas com setas, será capaz de fazer a distribuição eletrônica adequada para a maioria dos átomos que constituem a tabela periódica" (LDQ - B, p. 203) e "As regras que acabamos de ver são úteis apenas para que você aprenda alguns conceitos básicos da Química. No entanto, não valem para todos os elementos" (LDQ - D, p. 97, grifo dos autores).

Apesar de existir a previsão das exceções, o que entendemos ser um ponto positivo, pois mostra aos estudantes e aos professores que os modelos, elaborados pelos homens e mulheres da ciência, possuem certo alcance, um limite. Ou seja, conforme apontado pelos autores do LDQ F, "compreender a História da Ciência nos ajuda a entender as limitações da Ciência, bem como a refletir sobre o mundo que vivemos e pensar em novos modelos para explicá-lo" (SANTOS; MOL, 2016, p. 158). Superando, dessa forma, a concepção inadequada de que o conhecimento científico é algo pronto e acabado. Contudo, não há uma discussão maior por parte dos autores na tentativa de sugerir explicações para tal constatação, algumas sugestões podem ser consultadas, por exemplo, nos trabalhos de Meek e Allen (2002) e de Miessler e Tarr (2004). Somente os autores do LDQ - B justificam o porquê de não se dar uma explicação para as exceções, afirmando que

\begin{abstract}
essa discussão tem por base uma formulação matemática bastante avançada, que está muito além dos objetivos de um curso introdutório de Química. Assim, evitamos entrar em muitos detalhes sobre algumas características do modelo atual, pois isso significaria fazer simplificações que nem sempre ajudam a compreender a natureza da descrição da realidade atômica fornecida pela mecânica quântica (MORTIMER; MACHAD0, 2013, p. 198-199).
\end{abstract}

Sob este aspecto, os autores do LDQ - B, mostram que os conhecimentos matemáticos podem limitar o entendimento acerca do modelo atômico atual e das exceções da distribuição em subníveis de energia, pois envolve uma matemática avançada (cálculos diferencial e integral) que não é compatível com o nível cognitivo dos estudantes do nível médio. Talvez por essa complexidade os autores dos LDQ C, D, E e F tenham optado pela utilização de um modelo atômico mais simples, baseado apenas nos níveis, mesmo que esse modelo seja, por vezes, confuso para a determinação de configurações eletrônicas de metais de transição, como mostrado, para o Fe, no início da discussão da categoria "a configuração/distribuição eletrônica".

Além disso, vê-se que a afirmação dos autores do LDQ - B é corroborada, quando verificamos a complexidade da justificativa teórica, fornecida por Wong (1979), para as regras de Madelung. Atrelado a isso, Subramanian e Oliveira (1997) acrescentam que 0

[...] correto entendimento de estrutura atômica de átomos requer uma forte fundamentação nos princípios e métodos de mecânica quântica e espectroscopia atômica. Reconhecidamente, esta condição não pode ser satisfeita para os estudantes do colegial e iniciantes dos cursos de graduação. Qualquer pessoa que tenha experiência 
em lidar com estudantes nos diferentes níveis concordará que é sempre mais difícil ensinar e escrever acerca de um assunto complexo num nível elementar do que num nível avançado. As simplificações frequentemente inevitáveis resultam na introdução de informações errôneas e considerações equivocadas. (SUBRAMANIAN; OLIVEIRA, 1997, p. 313).

Nessa mesma linha, Rozentalski e Porto (2018, p. 455) observaram que 15 dos 16 livros de Química Geral analisados, destinados ao Ensino Superior, apresentaram uma abordagem essencialmente qualitativa para os diagramas de energia, cujo "objetivo principal [...] é apresentar o ordenamento relativo ou qualitativo dos níveis de energia dos orbitais, tendo como referência um eixo vertical que aponta em direção ao aumento de energia". Essa abordagem é justificada pelos autores pela não exigência de cálculo diferencial e integral nos livros de Química Geral. Podemos afirmar que o mesmo acontece com os LDQ destinados à Educação Básica.

Esses diagramas de energia ilustram visualmente o princípio de Aufbau (ou princípio da construção), que consiste em ir acrescentando os elétrons um a um aos níveis de energia para se obter a configuração eletrônica de átomos (SCERRI, 2019b). Park (2001) afirma que apesar do princípio de Aufbau possuir fundamento puramente teórico na interpretação eletrônica da tabela periódica, seu papel na teoria de Bohr e nas teorias quânticas subsequentes foi 0 de integrar resultados empíricos às teorias da época. Scerri (2013) acrescenta que o uso do princípio de Aufbau para prever configurações eletrônicas de átomos, é um ponto chave no ensino de Química. No entanto, a versão deste método que foi ensinada a gerações de estudantes apresenta algumas falhas como, por exemplo, a não previsão das configurações anômalas.

A proposição do princípio da construção data da década de 1920 (SCERRI, 2019b) para realizar o preenchimento dos níveis de energia que, em termos atuais, seguiria a seguinte sequência: $1 s \ll 2 s<2 p \ll 3 s<3 p<3 d \ll 4 s<4 p<4 d<4 f$ «ss... (SCHWARZ, 2013). Não é infalível, como mostrado acima, mas, de acordo com Riveros (2013), apresenta-se como um excelente ponto de partida para discussão teórica sobre a estrutura eletrônica dos átomos.

0 princípio de Aufbau é aplicado de forma inequívoca até o argônio $(Z=18)$, cuja configuração eletrônica é $1 s^{2}, 2 s^{2}, 2 p^{6}, 3 s^{2}, 3 p^{6}$, pois o próximo elétron deveria inaugurar o subnível 3d. No entanto, isso não ocorre, visto que o potássio $(Z=19)$ e 0 cálcio $(Z=20)$ apresentam as seguintes

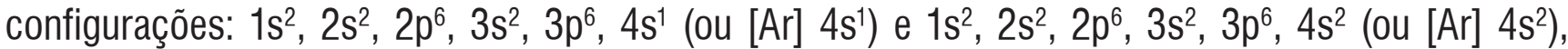
respectivamente. Isso ocorre devido ao que Sommerfeld (1928) chamou de defeito quântico, que é maior para um elétron no subnível 4s, em comparação com $03 \mathrm{~d}$. Em outras palavras, quanto maior a excentricidade das órbitas elípticas, maior será o defeito quântico e menor será a energia do subnível, assim, 0 subnível 4s deve ser preenchido antes do subnível 3d. Assim,

[...] para um dado n, a órbita com maior excentricidade será aquela que possuir menor valor de I. No caso de uma órbita muito excêntrica (como a 4s), o elétron penetra significativamente dentro do "caroço" formado pelos outros elétrons que circundam o núcleo, e assim fica sujeito a uma carga efetiva (positiva) maior do que a carga sentida por um elétron que permanecesse longe do núcleo. 0 elétron em questão terá, portanto, um "número quântico efetivo" menor do que o número quântico nominal, e assim poderá ter uma energia menor do que um elétron pertencente a uma camada eletrônica inferior. (BEZERRA, 2003, p. 512). 
Um problema adicional surge com os metais de transição, mais precisamente, a partir do escândio $(Z=21)$, em que a energia do subnível 3d torna-se menor que a do 4s (MOELLER, 1952; LEVINE, 2001), para maiores detalhes o leitor deve consultar a Figura 6 e verificar, inicialmente, que a energia dos subníveis varia com 0 aumento do número atômico e que para o potássio e cálcio $04 \mathrm{~s}$ possui energia menor que $03 \mathrm{~d}$, já para 0 escândio é 0 contrário. Neste sentido, por exemplo, a configuração esperada para o escândio seria $[\mathrm{Ar}] 3 \mathrm{~d}^{3}$, mas, isso não acontece, visto que a configuração observada é $[\mathrm{Ar}] 3 \mathrm{~d}^{1}, 4 \mathrm{~s}^{2}$.

Figura 6 - Variação da energia dos subníveis 3d e 4s para átomos polieletrônicos.

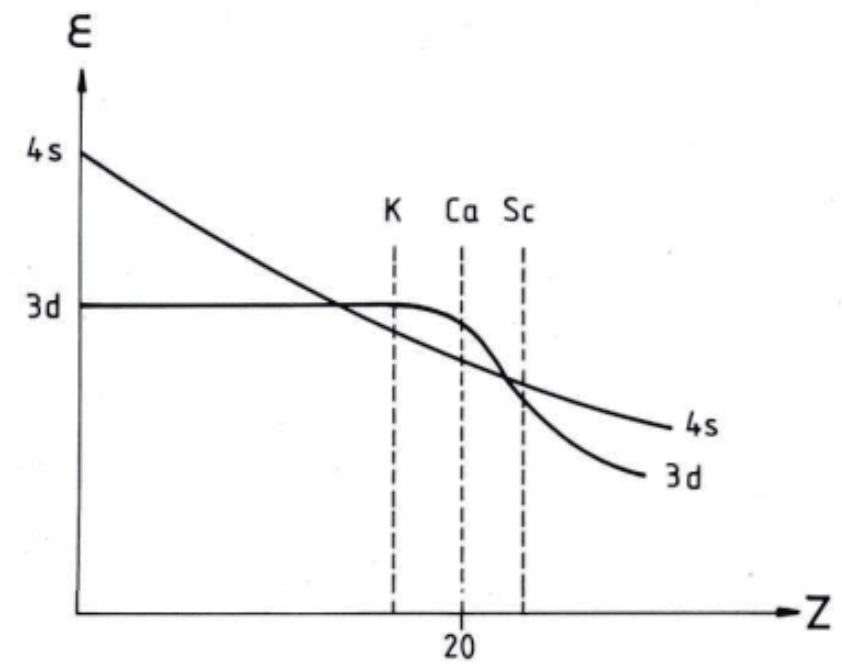

Fonte: Vanquickenborne, Pierloot e Devoghel (1994, p. 469).

Vanquickenborne, Pierloot e Devoghel $(1989,1994)$ investigaram o problema da inversão 3d-4s, para os metais de transição, utilizando métodos teóricos baseados em mecânica quântica e mostraram que a configuração mais estável, para o escândio, corresponde àquela obtida experimentalmente, por técnicas espectroscópicas. Os autores mostraram que, para qualquer átomo de metal de transição, as repulsões eletrônicas nos subníveis variam na sequência: $(4 s, 4 s)<(4 s, 3 d)<(3 d$, 3d), isto significa, que a ordem energética, para as possíveis configurações do escândio, varia na sequência: $[\operatorname{Ar}] 3 \mathrm{~d}^{1}, 4 \mathrm{~s}^{2}<[\operatorname{Ar}] 3 \mathrm{~d}^{2}, 4 \mathrm{~s}^{1}<[\operatorname{Ar}] 3 \mathrm{~d}^{3}$.

Essa problemática da inversão do subnível mais energético em átomos de elementos de transição também foi analisada, mas só encontramos explicitamente nos LDQ A e B. Para isso, vejamos a configuração, em termos de subníveis, do átomo de ferro $(Z=26)$ é $1 s^{2}, 2 s^{2}, 2 p^{6}, 3 s^{2}, 3 p^{6}, 4 s^{2}$, $3 \mathrm{~d}^{6}$, observa-se que a autora do LDQ - A atribuiu ao subnível $3 \mathrm{~d}^{6}$ como o mais energético, utilizando as regras $(n+l, n)$, enquanto os autores do livro LDQ - B atribuíram ao $4 s^{2}$, como subnível mais energético, para o mesmo átomo. Surgindo, mais uma divergência, dessa vez, no campo conceitual. Contudo, podemos afirmar que a atribuição correta seria a apresentada no LDQ - B, pois está em conformidade com os dados de Salehzadeh e Maleki (2016), em que acima de $Z=20$, tem-se $04 \mathrm{~s}$ 
como mais energético e não $03 \mathrm{~d}$. Assim, não há nenhuma razão científica para escrever a configuração eletrônica de elementos de transição externa do quarto período da tabela periódica como [Ar] 4s, 3d; pois a forma correta é [Ar] 3d, 4s.

A afirmação de Salehzadeh e Maleki (2016) é muito útil para o entendimento da formação de cátions bivalentes como, por exemplo, $\mathrm{Fe}^{2+} \mathrm{e} \mathrm{Co}^{2+}$. Já que 0 subnível $4 \mathrm{~s}$ é o mais energético e 0 mais externo, assim a configuração esperada para o $\mathrm{Fe}^{2+}$ será $[\mathrm{Ar}] 3 \mathrm{~d}^{6}$, como previsto pela autora do LDQ - A. No entanto a justificativa utilizada pela autora não é a mais adequada "0 cátion ${ }_{26} \mathrm{Fe}^{2+}$ possui 2 elétrons a menos, que serão retirados do nível e do subnível mais externos, 0 4s" (FONSECA, 2016, p. 175), faltou complementar que o subnível 4s é também o mais energético. Tal interpretação foi obtida por Vanquickenborne, Pierloot e Devoghel (1994), para o cátion $\mathrm{Co}^{2+}$, em que a configuração [Ar] $3 \mathrm{~d}^{7}$ possui menor energia que $[\mathrm{Ar}] 3 \mathrm{~d}^{5}, 4 \mathrm{~s}^{2}$; isto é, os elétrons devem ser "retirados" do subnível mais energético, 0 4s.

\section{CONSIDERAÇÕES FINAIS}

A análise dos Livros Didáticos de Química do ensino médio demonstrou que os autores atribuem a descoberta do diagrama (ou sequência) de distribuição eletrônica ora a Erwin Madelung (LDQ - A), ora a Linus Pauling (LDQ - B) ou a Niels Bohr (LDQ C, D e E), revelando uma contradição, o que pode confundir os professores e os estudantes, devido à imprecisão das informações históricas. No entanto, deve-se acrescentar a essa lista os nomes de Arnold Sommerfeld (1868-1951) e de Joseph Thomson (1856-1940), pois estes contribuíram com o primeiro diagrama de energia e a primeira proposição de configuração eletrônica, respectivamente. Sendo assim, acreditamos que os LDQ precisam passar por uma revisão neste ponto, de modo nos textos que surjam as contribuições dos cientistas envolvidos, mostrando as evoluções e as contradições acerca da configuração eletrônica, articulando as referências originais (ou primárias) com as secundárias, baseadas na nova historiografia da Ciência, visando uma reconstrução histórica mais abrangente e contextual desde a gênese do conceito, como proposto neste trabalho.

Por outro lado, existe um consenso de que com o diagrama de energia não é possível prever corretamente a configuração eletrônica de todos os átomos. Este é um ponto positivo, pois mostra que os modelos científicos apresentam limites e ajuda os estudantes a superarem uma concepção inadequada de Ciência, que está relacionada ao conhecimento científico ser algo pronto e acabado. Entretanto, observamos que não houve aprofundamento dessa questão nos LDQ, devido ao elevado grau de conhecimento matemático, como destacado no LDQ - B.

Por fim, concluímos que o diagrama de energia representa 0 ordenamento de distribuição dos elétrons nos subníveis e níveis, não sendo necessariamente uma distribuição eletrônica em ordem crescente de energia, mas sim, uma ordem preferencial de preenchimento de elétrons. 0 ferro, por exemplo, que pela distribuição apresenta $03 \mathrm{~d}^{6}$ (último) como subnível mais energético, mas essa posição é ocupada pelo $4 \mathrm{~s}^{2}$ que é o mais energético e o mais externo. Ademais, compreendemos ser importante 0 desenvolvimento de uma postura mais crítica quando analisamos livros didáticos, visto que alguns conteúdos, como demonstramos, estão equivocados ou apresentam erros históricos e conceituais que deveriam ter sido superados. 


\section{REFERÊNCIAS}

ALLCHIN, D. Pseudohistory and pseudoscience. Science \& Education, v. 13, p. 179-195, 2004.

ALLEN, L. C.; KNIGHT, E. T. The Löwdin challenge: Origin of the $n+l, n$ (Madelung) rule for filling the orbital configurations of the periodic table. International Journal of Quantum Chemistry, v. 90, p. 80-88, 2002.

ALMEIDA, A. V.; FALCÃO, J. T. R. A estrutura histórico-conceitual dos programas de pesquisa de Darwin e Lamarck e sua transposição para o ambiente escolar. Ciência \& Educação, v. 11, n. 1, p. 17-32, 2005.

BARDIN, L. Análise de conteúdo. São Paulo: Edições 70, 2016.

BELTRAN, M. H. R.; SAITO, F.; TRINDADE L. D. P. História da Ciência para formação de professores, Editora Livraria da Física: São Paulo, 2014.

BEZERRA, V. A. Schola quantorum: progresso, racionalidade e inconsistência na antiga teoria atômica. Parte I: desenvolvimento histórico, 1913-1925. Scientiae Studia, v. 1, p. 463-517, 2003.

BIANCO, A. A. G.; MELONI, R. A. 0 conhecimento escolar: um estudo do tema diagrama de Linus Pauling em livros didáticos de Química - 1960/1970. Química Nova na Escola, v. 41, n. 2, p. 148-155, 2019.

BOHR, N. The Theory of Spectra and Atomic Constitution. Cambridge: Press, 1922.

BRASIL. Guia de Livros Didáticos: PNLD 2018: Química: Ensino médio. - Brasília: Ministério da Educação, Secretaria de Educação Básica, 2017.

CACHAPUZ, S. et. al. (Orgs.). A Necessária Renovação do Ensino de Ciências. São Paulo: Cortez, 2005.

CARPENTER, A. K. 4s, 3d, What? Journal of Chemical Education, v. 60, n. 7, p. 562, 1983.

CHASSOT, A. Alfabetização científica: uma possibilidade para a inclusão social. Revista Brasileira de Educação, n. 22, p. 89-100, 2003.

CHAVES, L. M. M. P.; SANTOS, W. L. P.; CARNEIRO, M. H. S. História da Ciência no estudo de modelos atômicos em livros didáticos de Química e concepções de Ciência. Química Nova na Escola, v. 36, n. 4, p. 269-279, 2014.

DARSEY, J. A. A new approach for determining electronic configurations of atoms. Journal of Chemical Education, v. 65, n. 12, p. 1036, 1988.

FRANÇA, A. da C. G.; MARCONDES, M. E. R.; CARMO, M.; M. P. do. Estrutura Atômica e Formação dos Ílons. Química Nova na Escola, n. 4, p. 275-282, 2009.

FERNANDES, M. A. M; PORTO, P. A. Investigando a presença da história da ciência em livros didáticos de química geral Para 0 ensino superior. Quimica Nova, v. 35, n. 2, p. 420-429, 2012.

GAROFALO, A. Housing Electrons: Relating Quantum Numbers, Energy Levels, and Electron Configurations. Journal of Chemical Education, v. 74, n. 6, p. 709-710, 1997. 
GOUDSMIT, S. A.; RICHARDS, P. I. The order of electron shells in ionized atoms. Proceedings of the National Academy of Sciences - USA, v. 51, p. 664-671, 1964.

HAZLEHURST, T. H. Quantum numbers and the periodic table. Journal of Chemical Education, v. 18, n. 12, p. 580-581, 1941.

HOVLAND, A. K. Aufbau on a Chessboard. Journal of Chemical Education, v. 63, n. 7, p. 607, 1986.

JENKINS, R.; MANNE, R.; ROBIN, R.; SENEMAUD, C. Nomenclature, system for X-ray spectroscopy. (Nomenclature, symbols, units and their usage in spectrochemical analysis - VIII. Recommendations 1991). Pure and Applied Chemistry, v. 63, n. 5, p. 735-746, 1991.

KARAPETOFF, V. A chart of consecutive sets of electronic orbits within atoms of chemical elements. Journal of the Franklin Institute, v. 210, n. 5, p. 609-624, 1930.

KLECHKOWSKII, V. M. Justification of the rule for successive filling of $(n+l)$ groups. Soviet Physics JETP, v. 14, p. 334-335, 1962.

KURUSHKIN, M. Teaching Atomic Structure: Madelung's and Hund's Rules in One Chart. Journal of Chemical Education, v. 92, n. 6, p. 1127-1129, 2015.

LEITE, H. S. A.; PORTO, P. A. Análise da abordagem histórica para a tabela periódica em livros de química geral para 0 ensino superior usados no Brasil no século XX. Química Nova, v. 38, n. 4, p. 580-587, 2015.

LEVINE, I. N. Química Cuántica, 5 ${ }^{\text {th }}$ ed., Pearson Educación: Madrid, 2001.

LOPES, C. V. M. Modelos atômicos no início do século XX: da física clássica à introdução da teoria quântica. 2009. Tese (Doutorado em História da Ciência) - Pontifícia Universidade Católica, São Paulo, 2009.

LÜDKE, M.; ANDRÉ, M. E. D. A. Pesquisa em educação: Abordagens Qualitativas. 2. ed. Rio de Janeiro: E.P.U., 2018.

MATTHEWS, M. R. História, Filosofia e Ensino de Ciências: A Tendência Atual de Reaproximação. Caderno Catarinense de Ensino de Física, v. 12, n. 3, p. 164-214, 1995.

MADELUNG, E. Die Mathematischen Hilfsmittel des Physikers, $3^{\text {rd }}$ ed., Springer: Berlin, 1936.

MEEK, T. L.; ALLEN, L. C. Configuration irregularities: deviations from the Madelung rule and inversion of orbital energy levels. Chemical Physics Letters, v. 362, p. 362-364, 2002.

MIESSLER, G. L.; TARR, D. A. Inorganic Chemistry, $3^{\text {rd }}$ ed., New Jersey: Pearson Educational International, 2004.

MOELLER, T. Inorganic Chemistry - An advanced Textbook, John Wiley \& Sons: New York, 1952.

OKI, M. C. M. 0 conceito de elemento: da antiguidade a modernidade. Química Nova na Escola, n. 16, p. 21-25, 2002.

PARK, B. S. A principle written in diagrams: the Aufbau principle for molecules and its visual representations, 1927-1932. In: KLEIN, U. (Ed.). Tools and modes of representation in the laboratory sciences. Dordrecht: Kluwer, 2001. p. 179-198. 
PAULING, L. The nature of the chemical bond. 2nd ed. Ithaca: Cornell University Press, 1939.

PAULING, L. College Chemistry - An Introduction textbook of General Chemistry, $2^{\text {nd }}$ ed., W. H. Freeman: San Francisco, 1957.

PAULING, L. Química Geral. Rio de Janeiro: Técnicos e Científicos, 1982.

PIRES, R. 0.; ABREU, T. C.; MESSEDER, J. C. Proposta de ensino de química com uma abordagem contextualizada através da história da ciência. Ciência em Tela, v. 3, n. 1, p. 1-10, 2010.

PORTO, P. A. História e Filosofia da Ciência no Ensino de Química: Em busca dos objetivos educacionais da atualidade. In: SANTOS, W. L. P.; MALDANER, O. A. Ensino de Química em Foco, p. 159-180, 2011.

RIVEROS, J. M. 0 legado de Niels Bohr. Química Nova, v. 36, n. 7, p. 931-932, 2013.

ROZENTALSKI, E.; PORTO, P. A. Diagramas de energia de orbitais em livros didáticos de Química Geral: uma análise sob o viés da semiótica Peirceana. Ciência \& Educação (Bauru), v. 24, n. 2, p. 449-466, 2018.

SALEHZADEH, S.; MALEKI, F. The 4s and 3d subshells: Which one fills first in progressing through the periodic table and which one fills first in any particular atom? Foundations of Chemistry, v. 18, p. 57-65, 2016.

SANTOS, J. S. Análise sobre diferentes abordagens de configuração eletrônica de elementos apresentados em livros de química. 2011. Dissertação (Mestrado em Química) - Universidade Federal do Rio Grande do Norte, Natal, 2011.

SCERRI, E. R. Aufbau Mnemonics. Journal of Chemical Education, v. 68, n. 5, p. 445, 1991.

SCERRI, E. R. The trouble with the aufbau principle. Education in Chemistry, v. 50, n. 6, p. 24-26, 2013.

SCERRI, E. R. Happy 150"t birthday to the periodic table. CHEMISTRY: A European Journal, v. 25, p. 1-7, 2019 a.

SCERRI, E. R. Can quantum ideas explain chemistry’s greatest icon? Nature, v. 565, p. 557-559, 2019b.

SCHWARZ, W. H. E. The Full Story of the Electron Configurations of the Transition Elements. Journal of Chemical Education, v. 87, n. 4, p. 444-448, 2010.

SCHWARZ, W. H. E. (2013). 100 ${ }^{\text {th }}$ Anniversary of Bohr's Model of the Atom. Angewandte Chemie International Edition, v. 52, p. 2-13, 2013.

SEPINI, R. P.; MACIEL, M. D. A História da Ciência no ensino de ciências: 0 que pensam os graduandos em ciências biológicas. Revista de Educação, Ciências e Matemática, v. 6, n. 2, p. 97-114, 2016.

SOMMERFELD, A. Electronic structure of the atom and the Quantum-Theory. Memoirs and proceedings of the Manchester Literary and Philosophical Society, v. 70, n. 14, p. 141-151, 1925/1926.

SOMMERFELD, A. Atomic structure and spectral lines. $3^{\text {rd }}$ ed. Londres: Methuen, 1928. 
STEWART, P. J. Charles Janet: unrecognized genius of the periodic system. Foundations of Chemistry, v. 12, p. 5-15, 2010.

STONER, E. C. The distribution of electrons among atomic levels. Philosophical Magazine, v. 48, p. 719-736, 1924.

SUBRAMANIAN, N.; OLIVEIRA, S. F. Algumas Considerações sobre a Regra de Hund e a Estrutura Eletrônica de Átomos no Ensino de Química. Química Nova, v. 20, p. 313-318, 1997.

TARGINO, A. R. L.; BALDINATO, J. O. Abordagem histórica da lei periódica nas coleções do PNLD 2012. Química Nova na Escola, v. 38, n. 4, p. 324-333, 2016.

THOMSON, J. J. On the structure of the atom: an investigation of the stability and periods of oscillation of a number of corpuscles arranged at equal intervals around the circumference of a circle; with application of the results to the theory of atomic structure. Philosophical Magazine, v. 7, n. 39, p. 237-265, 1904.

UMEMOTO, K.; SAITO, S. Electronic configurations of superheavy elements. Journal of the Physical Society of Japan, v. 65 , n. 10 , p. $3175-3179,1996$.

VANQUICKENBORNE, L. G.; PIERLOOT, K.; DEVOGHEL. D. Electronic configuration and orbital energies: the 3d-4s problem. Inorganic Chemistry, v. 28, p. 1805-1813, 1989.

VANQUICKENBORNE, L. G.; PIERLOOT, K.; DEVOGHEL. D. Transition Metals and the Aufbau Principle, Journal of Chemical Education, v. 71, n. 6, p. 469-471, 1994.

VIDAL, P. H. 0.; PORTO, P. A. A História da Ciência nos livros didáticos de química do PNLEM 2007, Ciência \& Educação, v. 18, n. 2, p. 291-308, 2012.

WONG, D. P. Theoretical Justification of Madelung's Rule. Journal of Chemical Education, v. 56, n. 11, p. 714-717, 1979.

YI, P.-F. Letters to the editor. Journal of Chemical Education, v. 24, n. 11, p. 567, 1947.

RECEBIDO EM: 20 mar. 2021

CONCLUÍDO EM: 21 mai. 2021 
